\title{
La educación superior desde arriba y desde abajo: el caso del Hostos Community College en la ciudad de Nueva York
}

\author{
Higher Education from Above and Below: The Case \\ of Hostos Community College in New York City
}

\author{
José E. Cruz* \\ University at Albany-State University of New York \\ ORCID ID: 0000-0001-7235-229X \\ Recibido: $\quad 09 / 03 / 2020$ \\ Aceptado: $\quad 29 / 09 / 2020$
}

DOI: https://doi.org/10.20318/cian.2020.5793

\begin{abstract}
Resumen: Este artículo da cuenta del establecimiento y mantenimiento del community college Eugenio María de Hostos, localizado en el municipio del Bronx, en la ciudad de Nueva York, en conexión con reclamos de base por parte de los puertorriqueños y de otros grupos minoritarios en la ciudad durante los años ' 60 y '70. Este es un aspecto novedoso en su historia pues lo usual es que las instituciones de educación superior sean iniciativas "desde arriba." El establecimiento de Hostos ocurrió al mismo tiempo que la puesta en marcha de una política de libre acceso por parte de la universidad de la ciudad (CUNY). La lucha para evitar el cierre de Hostos, dic-
\end{abstract}

Abstract: This article traces the establishment and maintenance of Hostos Community College, located in the Borough of the Bronx in New York City, in connection with grassroots claims by Puerto Ricans and other minority groups during the ' 60 s and '70s. This connection is unusual in the history of institutions of higher education which tend to be top down initiatives. The establishment of Hostos took place in close proximity to the adoption and initiation of a policy of open admissions by the City University of New York (CUNY). Afterwards, the struggle to stop the closing of the college, per a decision taken in 1976, was similar to the struggle to establish the college.

\footnotetext{
*jcruz@albany.edu
} 
taminado en 1976, fue similar a la lucha para lograr su establecimiento. El artículo concluye que las iniciativas y esfuerzos "desde arriba" se combinaron de modo indirecto, directo y mediado con las presiones de estudiantes, profesores, activistas, y residentes "desde abajo," para lograr el establecimiento y la preservación de la institución, y sugiere que el éxito de la movilización social en general depende en gran parte de que su expresión se haga a través del poder más que desde las afueras del poder.

Palabras clave: CUNY, libre acceso, Hostos, Nueva York, Badillo, Bowker, Kibbee.
The article concludes that initiatives and efforts "from the top" combined with indirect, direct, and mediated pressures from students, faculty, activists, and residents "from below" to get the college established and to preserve it, and it suggests that to be successful social mobilization depends in great part on being channeled through power as opposed to from the margins.

Keywords: CUNY, Open Admissions, Hostos, New York, Badillo, Bowker, Bibbee.

Este artículo es un recuento del origen y la defensa del community college de la City University of New York (CUNY) Eugenio María de Hostos durante los años de 1960 y 70. Usando fuentes primarias y secundarias el artículo demuestra que Hostos no fue meramente el producto de una iniciativa de la administración de CUNY. A su establecimiento y defensa contribuyeron también luchas de base, en un proceso en el cual la idea de establecer el college germina y se concretiza en un contexto de efervescencia social y de militancia por parte de estudiantes y residentes de la ciudad de Nueva York entre los que se destacaron los puertorriqueños.

El artículo comienza con una descripción breve del contexto que sirve de base al eventual establecimiento de Hostos, pasando luego a la discusión de la política de libre acceso de CUNY, que es parte integral de las demandas de estudiantes de acceso a la educación superior. El artículo discute, después, tres momentos importantes en la historia de Hostos: la génesis de su establecimiento y su conexión con injerencias "desde abajo," su apertura formal en 1970, que concide con la adopción general de una política de libre acceso a CUNY, y la lucha por mejorar su planta física y evitar su cierre.

En la conclusión, se argumenta que Hostos fue un éxito conjunto de la acción simbiótica de administradores, estudiantes, residentes y políticos de la ciudad y en particular del municipio del Bronx. Este caso sugiere que para que la acción social "desde abajo" sea exitosa es preferible que esté vinculada a la acción administrativa y política "desde arriba," dentro de las instituciones relevantes.

El artículo hace uso extenso de reportajes periódisticos los cuales tienen consabidas limitaciones. Pero la información proviene de dos fuentes periodísticas de alta credibilidad, entre las cuales no hay contradicciones en 
su reportaje y cuyos datos encajan con los datos obtenidos en documentos oficiales y en la literatura existente sobre la experiencia de Hostos.

\section{El contexto}

Una de las carácteristicas más interesantes de la historia del community college Eugenio María de Hostos, localizado en el municipio del Bronx, en la ciudad de Nueva York, es la conexión de su establecimiento y defensa con reivindicaciones de base por parte de los puertorriqueños y de otros grupos de minoría en la ciudad durante los años ' 60 y ' $70 .{ }^{1}$ Esa conexión fue parte de un contexto socio-político de descontento y efervescencia social que indujo a cientos de miles de ciudadanos, no sólo en la ciudad de Nueva York sino también a través de Estados Unidos, Europa y América Latina, a ejercer y a reclamar sus derechos ciudadanos más allá del acto de la participación electoral. En Estados Unidos, esta es la época del movimiento de derechos civiles de los Afro-Americanos, que resulta ser la vanguardia de los movimientos ambientalistas, de mujeres, y de derechos sexuales de los años 70 .

En lo que respecta a la educación superior, algunos educadores notaban que ese contexto social estaba teniendo efectos de gran transcendencia. Según estos críticos, lo que estaba pasando en el sistema universitario era que el desacuerdo estaba siendo reemplazado por la protesta. Ese análisis reflejaba un juicio negativo hacia la movilización social. En la opinión de un educador que hizo su declaración sin identificarse: "Los estudiantes, sean o no concientes de ello, están pidiendo mucho más que un simple cambio de reglas. Ellos están desafiando una actitud y un sistema"2. Pero según el presidente del Georgia Institute of Technology, la realidad era que los estudiantes querían que la universidad participara más activamente en la solución de los problemas que aquejaban a las ciudades, los estados, y la nación ${ }^{3}$.

En el caso de Hostos, su historia es también parte de la historia del movimiento pro-independencia de Puerto Rico y de su vertiente socialista que en la ciudad de Nueva York se enfoca, entre otras cosas, en la reclamación de

${ }^{1}$ Edna Acosta-Belén, et al., "Adiós Borinquen querida:" La diáspora puertorriqueña, su historia y sus aportaciones (Albany, NY: CELAC, 2000), pp. 35-36; Carlos Rodríguez-Fraticelli, "Hostos Community College and the Puerto Rican Struggle for Equity in Education," CENTRO Journal of the Center for Puerto Rican Studies II:2 (1988), p. 25.

${ }^{2}$ Martin Gansberg, "Ferment on Campuses Challenges Rules," New York Times, May 6, 1968, p. 50.

${ }^{3}$ Ibid. 
acceso amplio de los puertorriqueños a las oportunidades que la ciudad históricamente había ofrecido a grupos poblacionales de immigrantes y de clase desventajada. Serrano, por ejemplo, ubica claramente el activismo estudiantil puertorriqueño en el marco de un estado general de levantamiento social y político en Estados Unidos en el que el movimiento en contra de la Guerra de Vietnam en particular jugó un papel muy importante. Además, la lucha estudiantil en Puerto Rico fue otra fuente de activismo como resultado de sentimientos nacionalistas y anticoloniales de muchos jóvenes Boricuas en Nueva York ${ }^{4}$.

La conexión entre el establecimiento de Hostos y las luchas generadas en ese contexto, que aquí catalogamos como una interacción "desde arriba y desde abajo," es un aspecto novedoso en la historia de Hostos pues lo usual es que las instituciones de educación superior sean iniciativas desde arriba. La documentación disponible revela que Hostos fue parte de la idea de los community colleges en CUNY como un punto de acceso a la educación superior adaptado a las circunstancias educativas de grupos que se concebían como necesitados de un espacio institucional de preparación profesional más allá del bachillerato, pero también como lugar de preparación para una educación más avanzada a nivel universitario. Esa documentación sugiere que el contexto social de la época jugó un papel importante tanto en la toma de decisiones académicas en el seno de la administración de CUNY como en la participación social de base.

\section{Antesala del libre acceso}

Hostos es concebido en 1964 y la decisión de ponerlo en marcha es de 1968, unos meses antes de que se adoptara una política de admisiones de libre acceso. No obstante, comenzaremos observando la discusión de los antecedentes de la política y luego de la política en sí y lo hacemos por varias razones. Primero, se trata de una aproximación conceptual amparada en la propuesta de Skowronek y Orren y que propone que para trazar el desarrollo político no es imprescindible seguir un curso estrictamente cronológico ${ }^{5}$. Además, el orden de la discusión está basado en la distinción entre la prefiguración de un proyecto institucional y su forma de concretarse físicamente. Es decir, no

${ }^{4}$ Basilio Serrano, "'Rifle, Cañón, y Escopeta', A Chronicle of the Puerto Rican Student Union," en Andrés Torres and José E. Velázquez, eds., The Puerto Rican Movement, Voices from the Diaspora (Philadelphia: Temple University Press, 1998), pp. 125, 127-28.

${ }^{5}$ Stephen Skowronek and Karen Orren, The Search for American Political Development (Cambridge, UK: Cambridge University Press, 2004), pp. 1-32. 
es lo mismo imaginar un community college que establecerlo en un edificio específico con aulas y estudiantes. Aquí decidimos usar la fecha de apertura de Hostos en el 1970 como el momento clave del orden cronológico. En tercer lugar, la política de libre acceso es vislumbrada por la Junta de Educación superior en 1966 y en este caso la diferencia entre conceptualización e implementación no surge de una diferencia entre lo ideal y lo material. Es decir, en ambos casos se trata de una idea y es una idea que sirve de marco al proyecto de los community colleges.

Según el rector de CUNY, Albert H. Bowker, la decisión que CUNY tomó en 1967 de establecer un mecanismo de consulta con la comunidad, reflejaba el deseo de la institución de incluir la participación de base en la toma de decisiones por parte de la administración universitaria ${ }^{6}$. Esta era una aspiración que surgía de la combinación de cálculos demográficos por parte de Bowker, así como también de la filtración desde abajo hacia arriba de los reclamos de la militancia del momento. Era una aspiración optimista que no todo el mundo compartía sin reserva, especialmente después que Hostos abriera sus puertas en un contexto de múltiples privaciones comunitarias ${ }^{7}$. En ese mismo año, un estudio realizado por el Women's City Club of New York concluyó que en vez de expandir los community colleges existentes, CUNY debía crear más, especialmente en áreas necesitadas de la ciudad. El Club llegó a esa conclusión no a base de la opinión de peritos sino tras entrevistar a un grupo de estudiantes de áreas necesitadas que se veían obligados a salir de sus vecindarios para estudiar ${ }^{8}$.

En 1967, Bowker decía, además, que establecer un community college en un área desfavorecida de la ciudad podía ser una manera de aumentar la participación eventual de sus jóvenes en la universidad y de contrarrestar la tasa de deserción escolar en dichas áreas vecinales ${ }^{9}$. Se refirió explícitamente al vecindario de Harlem, pero bien podía haber estado hablando del Sur del Bronx. Esa manera de pensar, "desde arriba," fue un factor importante en el desarrollo de la educación superior en Nueva York a nivel de los community colleges durante los años '60 y '70. De hecho, al año siguiente, Bowker

6 "Faculty and Students of City U. Will Share in Decision-Making," New York Times, October 1, 1967, p. 63.

${ }^{7}$ Barry Castro, "Hostos: Report from a Ghetto College," Harvard Educational Review 44:2 (May 1974), p. 270.

${ }^{8}$ Martin Gansberg, "2-Year Colleges Praised In Study," New York Times, October 22, 1967, p. 78.

${ }^{9}$ Leonard Buder, “Colleges in Harlem Urged by Bowker," New York Times, January 19, 1967, p. 1. 
cementó la idea de que Hostos había sido concebido totalmente "desde arriba" al declarar públicamente que "el originador y la fuerza propulsora" de la idea de un community college en el Sur del Bronx había sido el entonces presidente del municipio del Bronx, Herman Badillo ${ }^{10}$.

En 1966, una vez que Badillo había llegado al cargo un año antes, la Junta de Educación Superior de CUNY -precursora de la actual Junta Fiduciaria [Board of Trustees] y organismo responsable por la reglamentación del complejo de facultades que constituyen la universidad de la ciudad- reconoció que la universidad pública de la ciudad estaba excluyendo sistemáticamente de sus aulas a los miembros de grupos poblacionales que más necesitaban acceso a la educación superior. Ese reconocimiento fue uno de los primeros pasos hacia la adopción general de la política de libre acceso al sistema de CUNY, que ocurre al mismo tiempo que la apertura de Hostos Community College ${ }^{11}$.

\section{Libre acceso a CUNY}

La política de libre acceso al sistema de CUNY no fue el resultado exclusivo de un esfuerzo desde arriba. También hubo presiones desde abajo por parte de activistas comunales que encontraron un aliado en Albert Bowker. Según Julius C.C. Edelstein, uno de los arquitectos de la política, "Al Bowker fue quien realmente concibió la idea de libre acceso y yo fui su ejecutor"12. Pero aún así, antes de que hubiera acciones directas "desde abajo," la presión de las masas se hizo sentir indirectamente en las elucubraciones de Bowker. Según Edelstein, Bowker "era un matemático y él había hecho las proyecciones de lo que sería la matrícula en los colegios de la ciudad si no se aliviaban los requisitos de admisión para permitir la matrícula de estudiantes en desventaja académica"13.

A finales de los años 60, Edelstein también articuló de modo indirecto el sentir "desde abajo" al invocar el espectro de las masas ante la Junta de Educación Superior, argumentando que dado el clima de descontento y protesta prevaleciente en las universidades a nivel nacional, si CUNY no hacía algo para

\footnotetext{
${ }^{10}$ Martin Tolchin, “Jobless to Train for Medical Work," New York Times, May 25, 1968, p. 37.

${ }^{11}$ Albert H. Bowker, "City U. Faces Up to the Urban Realities, New York Times, January 12, 1970, p. 82.

${ }^{12}$ Karen W. Arenson, "A CUNY Revolutionary Looks Back," New York Times, March 20, 2002, p. B9. Todas las citas han sido traducidas del inglés por el autor.

${ }^{13}$ Ibid.
} 
aumentar la matrícula de los grupos minoritarios de la ciudad, que para esa época era de menos de un 2\%, el sistema iba a ser arrasado por lo que llamó "trigre que acecha en la entrada"14. El miedo era que estos grupos, como el tigre de la obra de Jean Giraudoux a la que aludía la referencia de Edelstein, fuesen provocados por la negligencia del sistema a atacarlo con alevosía ${ }^{15}$.

La evaluación del sistema de admisiones de CUNY se vislumbraba en el plan maestro de la Junta del año 1968 para aumentar las oportunidades educativas de jóvenes Afro-Americanos y puertorriqueños. A esos efectos, en su reunión del 27 de mayo de 1968, la Junta adoptó una resolución para establecer un programa experimental de admisiones en Brooklyn College. Después de consultar con estudiantes, facultad y líderes de la comunidad, el Brooklyn College Presidential Advisory Committee on Educational Opportunity recomendó a la Junta un programa a través del cual Brooklyn admitiría unos 200 estudiantes Afro-Americanos y puertorriqueños de vecindarios pobres. Los estudiantes serían matriculados en clases regulares y tendrían el beneficio de tutorías y consejería individual por parte de los miembros de la facultad ${ }^{16}$.

En agosto de 1968, la Junta modificó su objetivo de manera urgente. En ese tono de urgencia se especifica el sentir del ambiente social de base. De modo indirecto, el sentir de la comunidad, que es a su vez eco del ambiente de militancia y de demandas del momento, se hace presente en las deliberaciones de la Junta. De suerte que, en su reunión del 1 de agosto de 1968, la Junta resolvió acelerar la puesta en marcha de una política de admisión para todo el sistema que eventualmente resultó ser la de libre acceso. Se consideraba que la ciudad estaba en una situación de "emergencia social a consecuencia de la existencia de profundas desigualdades e injusticias sociales y de un estado de frustración individual y de grupo masiva que resulta en tensiones y resentimientos inter-grupales." Para la Junta, esto representaba un "peligro social que demanda nuestra consideración, deliberación y acción inmediata"17.

Esa mentalidad era parte de un síndrome que rebasaba los límites de la ciudad. Según indica Francis-Fallon, a nivel nacional, las elites de los partidos Demócrata y Republicano, coincidían en creer que el gobierno debía tomar medidas para ayudar a los puertorriqueños y a los mexicanos para "prevenir la pérdida de la gente de habla hispana al resentimiento y la

\footnotetext{
${ }^{14}$ Ibid.

${ }^{15}$ Jean Giraudoux, Tiger at the Gates, translated by Christopher Fry (New York: Oxford University Press, 1955).

${ }^{16}$ Board of Higher Education of the City of New York, Proceedings of the Board of Higher Education of the City of New York, 1968, The Municipal Library, City of New York, p. 112.

${ }^{17}$ Ibid., p. 180.
} 
violencia"18. Según Barry Goldwater, senador Republicano y otrora candidato presidencial, el gobierno debía intervenir para contrarrestar la agitación de los radicales y prevenir su éxito. ${ }^{19}$

A nivel nacional había otras voces que justificaban la ayuda del gobierno desde una posición completamente opuesta a la que veía a los puertorriqueños como revolucionarios en ciernes. En ese discurso, los puertorriqueños eran dóciles, fieles a la ley y el orden, gentiles y amables, religiosos y hasta tímidos. En esta visión, ellos no recurrían a la violencia o el desorden, sino que combatían su frustración ayudándose entre sí. En vez de romper ventanas o quemar edificios, ellos sufrían en silencio y eran renuentes a pedir ayuda ${ }^{20}$. Pero claro, esa visión era un recurso retórico que quedaba desmentido por los motines de 1966 en Chicago, y los de 1964, 1967, y 1968 en Nueva York ${ }^{21}$. Aunque esas acciones no exigían un nuevo community college, en Nueva York fueron parte del cálculo elitista en esa dirección.

Dentro de la Junta de Educación Superior, después del establecimiento de Hostos y a tono con la idea de que la movilización comunitaria requería una respuesta institucional, la voz de la comunidad fue articulada por María Josefa Canino, una joven profesora, activista, e intelectual puertorriqueña, durante su membresía del 1969 al 1974. Según Canino, el período de su nombramiento:

Fue uno de muchísima tensión y se palpaba el disgusto con las movilizaciones estudiantiles en CCNY [City College of New York] y demás recintos incluyendo a Hostos. A todo momento estaba envuelta en la defensa del establecimiento de Hostos, de las demandas estudiantiles para aumentar la matrícula y reclutamiento de estudiantes, facultad y personal de origen 'minoritario', de la admisión abierta, y de los programas complementarios académicos como SEEK y Upward Bound ${ }^{22}$.

Canino no fue la única que de forma mediada hizo presente la voz de la comunidad en el seno de la Junta, pero sus intervenciones fueron de las más notables.

\footnotetext{
${ }^{18}$ Benjamin Francis-Fallon, The Rise of the Latino Vote, A History (Cambridge, MA: Harvard University Press, 2019), p. 153.

${ }^{19}$ Ibid. p. 154.

${ }^{20}$ Ibid., p. 156.

${ }^{21}$ Felix Padilla, Puerto Rican Chicago (Notre Dame, IN: University of Notre Dame Press, 1987), pp. 144-179; Michael Rodríguez-Muñiz, "Riots and Remembrance: Puerto Rican Chicago and the Politics of Interruption," CENTRO Journal XXVIII: II (Fall 2016): 204-217; José E. Cruz, Liberalism and Identity Politics, Puerto Rican Community Mobilization and Collective Action in New York City (New York: Centro Press, 2019), pp. 62-63; 80-83.

${ }^{22}$ Comunicación personal con María Josefa Canino, 2 febrero 2020.
} 
Inicialmente el nuevo régimen de admisiones estaba contemplado para comenzar en 1975 pero resultó efectivo en septiembre de 1970. El adelanto de cinco años fue el resultado de marchas, concentraciones, huelgas y otros actos de desafío por parte de estudiantes y profesores en el año de $1969^{23}$. En Columbia University, cientos de estudiantes ocuparon dos edificios demandando libre acceso para estudiantes Afro-Americanos y puertorriqueños. Esta protesta fue interesante pues extendía el alcance del reclamo de libre acceso a una universidad privada. En Queens College, en dos ocasiones, la movilización estudiantil se tornó violenta. En el City College de CUNY, una huelga estudiantil que demandaba estudios sobre historia y cultura de Puerto Rico logró obtener el apoyo de varias organizaciones profesionales y comunitarias y el presidente del college llegó a declarar que, en principio, apoyaba las demandas de los estudiantes de una escuela separada de estudios para Afro-Americanos y puertorriqueños ${ }^{24}$.

Esa presión de base fue crítica pero no se puede negar que parte de su éxito se debió a que la movilización social desde abajo tuvo importantes aliados desde arriba: en la administración de CUNY y por parte del alcalde republicano de la ciudad de Nueva York en ese momento, John Lindsay, entre otros $^{25}$. Pero la presión "desde abajo" es el factor inmediato que hace que el 25 de mayo de 1969 el City College de CUNY se adelante a la Junta de Educación Superior al acordar por separado con grupos de estudiantes Afro-Americanos y puertorriqueños que la mitad de la clase de 1970 sería de estudiantes desfavorecidos, independientemente de sus calificaciones académicas. A pesar de algunas objeciones, CUNY adoptó la política para todo el sistema para que coincidiera con la fecha seleccionada por el City College ${ }^{26}$.

${ }^{23}$ Stephen Brier, "Why the History of CUNY Matters: Using the CUNY Digital History Archive to Teach CUNY's Past," Radical Teacher 108 (Spring 2017), pp. 31-32.

24 "Estudiantes Columbia Desafían Ley," El Diario-La Prensa, 1ero de mayo de 1969, p. 3. "Estudiantes Asaltan Queens College," El Diario-La Prensa, 14 de enero de 1969, p. 3; "Violencia en Queens College," El Diario-La Prensa, 2 de mayo de 1969, p. 2; "Apoyan a Estudiantes del C.C.," El Diario-La Prensa, 2 de mayo de 1969, p. 4; "Apoyo Estudiantes del CC: Gallagher," El Diario-La Prensa, 2 de mayo de 1969, p. 3.

${ }^{25}$ Board of Higher Education of the City of New York, Master Plan of the Board of Higher Education for the City University of New York, 1968: 1970, September 1, 1970, New York State Library and Archives, p. 20; M.S. Handler, "City Funding is Key to Open Admissions," New York Times, December 18, 1969, p. 50. El apoyo de Lindsay tenía condiciones: él quería que el estado proveyera los fondos necesarios y que el plan garantizara la admisión de los estudiantes que eran elegibles bajo el régimen existente. Ver M.A. Farber, "Open-Entry Plan On City U. Scored," New York Times, October 23, 1969, p. 1.

${ }^{26}$ Lacey Fosburgh, "City U. Boycotted by Students Protesting Proposed Fee Rise," New York Times, April 30, 1970, p. 36; "Boycott Continues at City University," New York Times, May 2, 
Concepto de la política de libre acceso

El concepto de política de libre acceso fue más allá del mero proceso de admisión y su propósito incorporó más que un simple deseo de hacer la universidad más accesible a los graduandos de escuela secundaria. Mayor acceso fue el componente clave de la política: a su amparo, todo bachiller podía ser admitido en el sistema de CUNY independientemente de lo que dijera su transcripción académica. Pero la política tenía otros aspectos sustantivos.

No se trataba de abrir las puertas de la universidad para que los estudiantes entraran sin cumplir con ningún tipo de requisito, sino de combinar el acceso amplio con programas especialmente diseñados para atender a las necesidades de estudiantes desventajados social y económicamente. Además, la política contemplaba un nuevo sistema de calificaciones para los estudiantes de primer año, alternativas curriculares para el cumplimiento de los requisitos del grado, el establecimiento de un Instituto del Arte del Aprendizaje, matrícula adelantada para nuevos estudiantes, y cursos sin crédito para remediar deficiencias académicas. La propuesta incluía que, una vez terminados los cursos, los estudiantes obtuvieran crédito académico después de tomar con éxito exámenes de colocación avanzada ${ }^{27}$.

1970, p. 13. El ex-alcalde de la ciudad Robert Wagner reaccionó a la decisión diciendo que la consideraba "personalmente repugnante." Otro opositor del acuerdo fue Herman Badillo quien alegaba que ese sistema iba a resultar en "dos colegios separados y desiguales de calidad incierta." Ver Murray Schumach, "Admissions Plan for C.C.N.Y. Stirs a Major Dispute," New York Times, May 25, 1969, p. 1; "Acuerdo Inicial Entre el C.C. y los Estudiantes," El Diario-La Prensa, 25 de mayo de 1969, p. 4 y "Badillo se Opone a Plan De Admisión en C. College," El Diario-La Prensa, 26 de mayo de 1969, p. 2. Durante el transcurso de entrevistas con líderes estudiantiles puertorriqueñas de esa época, el profesor de Lehman College Xavier Totti descubrió que algunos estudiantes Boricuas sólo estaban interesados en mayores admisiones para Afro-Americanos y puertorriqueños y que se oponían al libre acceso pues creían que esa política les desvalorizaría la credencial de Lehman. Comunicación personal con Xavier Totti, 7 febrero 2020. Algunos estudiantes protestaron porque según ellos no iban a poder disfrutar de los beneficios económicos de la nueva política o en oposición al mecanismo adoptado para sufragar sus costos. Ver "Student Meeting At Queens Rejects Open Enrollment," New York Times, March 15, 1970, p. 88; Arnold H. Lubasch, "City U. Students Boycott Classes," New York Times, March 18, 1970, p. 31. Desde la izquierda, la Students for a Democratic Society alegaba que la política era fraudulenta porque no se veía que fuera a ser adecuadamente financiada. Ver M.A. Farber, "Open-Entry Plan...”

${ }^{27}$ Robert D. McFadden, "Plan Urged to Aid Open Admissions," New York Times, February 15, 1970, p. 31. 
La política de libre acceso también contemplaba un grado mayor de cooperación entre la universidad y el sistema de educación pública a nivel secundario. El objetivo era aumentar la capacidad de los profesores a ese nivel mediante prácticas de entrenamiento y certificación que ayudaran a mejorar la calidad del profesorado. Se entendía que esto, a su vez, aumentaría la preparación de los estudiantes, incrementando así la posibilidad de éxito una vez dentro del sistema universitario.

Un aspecto polémico de la política de libre acceso, expresado por Bowker, fue el relativo a la secuencia del estudio académico. Según Bowker, la filosofía de la educación general debía ser revisada. La revisión que él proponía consistía en enfatizar el estudio especializado temprano en la carrera académica de los estudiantes. Se trataba de invertir el orden de estudio de las materias de orden general y de orden más específico o técnico.

Una presunción detrás de la propuesta inversión era que, al menos al principio, los estudiantes iban a estar más interesados en el estudio de materias especializadas o prácticas que en el estudio de materias más relativas al conocimiento humano en general. La otra presunción era que el estudio de materias de mayor interés para los estudiantes al principio de su carrera les mantendría interesados a la misma vez que le daba tiempo a los community colleges o a la universidad de encaminarlos hacia el estudio de materias más generales si así lo deseaban.

La política de libre acceso fue conceptualizada como parte de la misión de la universidad pública. Esa misión era servir a la mayoría de los residentes de la ciudad, dándoles la oportunidad de obtener un grado universitario al mayor número posible de estudiantes, y especialmente a aquellos que, por razones ajenas a su talento y capacidad, corrían el riesgo de no poder disfrutar de esa oportunidad. En consonancia con esa misión, la política contemplaba que la educación al nivel de los colleges fuese complementada por unidades de transición entre la escuela secundaria y los colleges, que en el sistema estadounidense son, en efecto, universidades.

Estas unidades de transición eran el sistema de community colleges de los que Hostos pasó a formar parte. Al estar anclados en vecindarios específicos, los community colleges harían que la política de libre acceso combinara la accesibilidad procesal con la geográfica. Según declaraciones de Bowker en 1970, el año en que Hostos abrió sus puertas, este sistema "adquirirá más importancia en la próxima década y necesita ser fortalecido y expandido" 28 .

${ }^{28}$ Bowker, "City U. Faces...” 


\section{El Caso de Hostos}

El establecimiento de Hostos fue pronosticado en la segunda revisión al plan maestro de 1964 de la Junta de Educación Superior, cuando ésta reconoció que los community colleges existentes no tenían la capacidad para manejar la matrícula que se esperaba en CUNY para $1975^{29}$. Es importante recalcar que ese presagio no se materializó hasta 1970 y lo fue en gran parte como resultado de efectos contextuales relativos a la efervescencia social más recrudecida entre los puertorriqueños durante ese período, es decir, como resultado de presiones "desde abajo."

En 1967, como ya se ha dicho, CUNY estableció un mecanismo que articulaba el sentir de la facultad y los estudiantes y lo incorporaba al plan de 1968, que es el que estipula la creación de Hostos. En 1968, al mismo tiempo que la Junta de Educación Superior discutía la necesidad de ampliar las oportunidades de acceso a CUNY, ésta estimaba que entre 1968 y 1975, el sistema contaría con cuatro nuevos community colleges $^{30}$. Pero en ese año Hostos es sólo una propuesta que es llevada a la práctica de manera acelerada en 1970 a raíz de la agitación social que culmina en la adopción de la política de libre acceso en el City College de CUNY en el 1969 y en el sistema en general en 1970.

En su reunión del 22 de enero de 1968 la Junta decidió, en principio, establecer el Community College Número 8, que fue como se designó al college antes de otorgarle el nombre de Eugenio María de Hostos. En esa reunión, la única razón que la Junta ofreció para justificar su decisión fue la falta de espacio, lo cual oscurecía el papel jugado por el contexto de protesta y movilización social. Según la Junta, un análisis de la matrícula proyectada para el período de 1967 a 1980 indicaba que en el otoño de 1968 la matrícula iba a exceder el espacio disponible en los community colleges existentes y que para 1980 el déficit iba a ser monumental. Por lo tanto, la Junta concluyó que "si la Universidad realmente desea cumplir su promesa de proveer oportunidades de educación superior para los residentes de la ciudad de Nueva York," iban a hacer falta más community colleges. La referencia a la promesa de ofrecer

${ }^{29}$ Inmaculada Lara-Bonilla, "Crafting a Latina/o Higher Education Rights Discourse in New York: The Founding and "Saving" of Eugenio María de Hostos Community College," New York History 97: 2 (Spring 2016), p. 201.

${ }^{30}$ Board of Higher Education of the City of New York, Master Plan of the Board of Higher Education for the City University of New York, 1968, July 1, 1968, New York State Library and Archives, p. xiii. 
mayor acceso deja entrever el papel jugado por el contexto de movilización y de reclamos de base, que estaban centrados en la idea de mayor acceso ${ }^{31}$.

En esa reunión de enero, la Junta ordenó la preparación de un informe que especificara en detalle cómo se iba a implementar su decisión ${ }^{32}$. Luego, en su reunión del 25 de marzo de 1968, la Junta aceptó y formalizó la participación de la comunidad en el proceso de implementación de su decisión de establecer community colleges adicionales, Hostos incluído, al declarar que era importante tomar en cuenta de forma sistemática el sentir de la comunidad expresada a través de sus representantes ${ }^{33}$. La referencia específica en este caso fue a la comunidad de Bedford-Stuyvesant, donde se iba a localizar el Community College Número 7, pero es lógico inferir que ese sentir se extendía a la participación comunitaria en el proceso de establecer a Hostos.

La decisión formal para establecer a Hostos fue tomada el 22 de abril de 1968 en la parte de la reunión de la Junta de Educación Superior designada especialmente para tratar asuntos referentes a los community colleges de CUNY. En ese momento, la Junta tenía 53 miembros, dos de los cuales eran puertorriqueños: Louis Núñez y Luis Quero Chiesa. En esa ocasión en particular, no hay reconocimiento alguno del sentir de la comunidad en la decisión de la Junta y la injerencia comunal sólo puede inferirse a base de la presencia de Quero Chiesa y Núñez. De hecho, en esa reunión Núñez mencionó que los programas para minorías no satisfacían las necesidades de los puertorriqueños y criticó el sistema de admisiones existente como demasiado rígido ${ }^{34}$.

La decisión formal fue hecha al amparo del informe que la Junta había comisionado en enero. Ese informe, titulado "A Proposal for the Establishment of Community College Number Eight," iba más allá de la preocupación inicial de la Junta respecto a la capacidad de las unidades existentes de acomodar al creciente estudiantado. Pero las minutas de la reunión resumen la decisión con unas meras 99 palabras que determinan el establecimiento de lo que vino a ser Hostos "efectivo septiembre de 1969 o lo más pronto posible después de esa fecha,"35 que terminó siendo septiembre de 1970.

Así, la expansión de la que hablaba Bowker en 1970, comenzó precisamente en ese año. La apertura en septiembre de 1970 del Hostos Community College y del Community College Número 9 -que luego fue nombrado La Guardia Community College- representó un aumento de un 33\% del número

\footnotetext{
${ }^{31}$ Board of Higher Education of the City of New York, Proceedings..., p. S-9.

${ }^{32}$ Ibid., p. S-7.v

${ }^{33}$ Ibid., pp. S-44-45.

${ }^{34}$ Ibid., p. 17.

${ }^{35}$ Ibid., p. S-56.
} 
existente de community colleges en el sistema de CUNY. Conjuntamente con el resto de los colleges, Hostos iba a ser responsable de la enseñanza de 21.528 estudiantes admitidos en el sistema en el otoño de $1970^{36}$, para un promedio de un poco más de 2.600 estudiantes por unidad. La matrícula de estudiantes puertorriqueños en el sistema en su totalidad subió del 2,4 en 1967 al 11,7\% en 1970, pero Hostos comenzó a funcionar con solo 623 estudiantes ${ }^{37}$.

Como sugiere el nombre del colegio, anunciado a los medios por el alcalde John Lindsay el 29 de septiembre de $1969,{ }^{38}$ la institución tenía como propósito fundamental ser de los puertorriqueños, para los puertorriqueños, aunque desde el principio Hostos tuvo una matrícula mixta de $20 \%$ de estudiantes blancos, $40 \%$ Afro-Americanos, y $40 \%$ puertorriqueños. ${ }^{39}$

\section{La injerencia "desde abajo"}

En el caso de Hostos, la conexión con esfuerzos "desde abajo" se venía fraguando desde principios de 1960. Aunque es cierto que la documentación de acciones comunitarias conducentes a la aprobación de Hostos por la Junta es deficiente ${ }^{40}$, es posible detectar la presión "desde abajo" en varias instancias. Se puede inferir, por ejemplo, en las antes mencionadas elucubraciones del rector Bowker. También está presente en los planteamientos hechos por su mano derecha, Julius Edelstein, y en las intervenciones de representantes comunitarios como Louis Núñez y María Josefa Canino, aunque en el caso de Canino, esa injerencia tuvo como foco fortalecer a Hostos.

También está el hecho de que el autor del informe que discute los pormenores del establecimiento del colegio, Cándido de León, era un profesional buen conocedor de la comunidad. En su momento, de León había sido director del programa de educación superior de la organización Mobilization for Youth (MFY) en el Bajo Manhattan, un área de concentración puertorrique-

\footnotetext{
${ }^{36}$ Leonard Buder, “More Top Students Applying at City U. Despite 'Open Door,'” New York Times, June 14, 1970, p. 1.

${ }^{37}$ M.A. Farber, "Entrants Put Minority Groups' Rolls at 33\%," New York Times, September 14, 1970, p. 1; https://www.hostos.cuny.edu/About-Hostos/The-History-of-Hostos<Consultado 25 enero 2020>

${ }^{38}$ Tomas Lopez, "An American Necessity:" The Politics of Survival at Hostos Community College, New York, 1970-78, Honors Thesis, Department of History, Duke University, April 14, 2006, p. 3.

${ }^{39}$ M.A. Farber, "City U. Is Adjusting to the Sharp Increase in Number of Freshmen," New York Times, March 26, 1971, p. 21.

${ }^{40}$ Lara-Bonilla, “Crafting...," p. 201.
} 
$\tilde{n} a^{41}$. Y bien se sabe que MFY era una organización que operaba bajo el principio de "la mayor participación factible" que enmarcó la relación entre el pueblo y el gobierno federal durante la época de la Guerra Contra la Pobreza ${ }^{42}$.

Una referencia específica por parte de Bowker que denotó la presión indirecta de la comunidad al amparo del principio de mayor participación factible, ocurrió en la reunión de la Junta del 25 de marzo de 1968. En esa ocasión, Bowker recomendó que un comité de la Junta se reuniera con miembros de la comunidad para discutir los planes de CUNY para especificar su papel en la comunidad. Además de la incorporación implícita del postulado de la Guerra Contra la Pobreza en su planteamiento, esta sugerencia llegaba en el contexto de la bien conocida preocupación de Bowker con el futuro de la juventud Afro-Americana y puertorriqueña en el sistema. Su interés era que hubiese "una participación comunal amplia" en esas deliberaciones, aunque podría aclararse que para Bowker la "comunidad" significaba "un grupo de ciudadanos distinguidos" que representaran la comunidad ${ }^{43}$.

Así mismo, en el momento de esta decisión, se llevaron a cabo acciones comunales que partían de la preocupación de los administradores de CUNY con el futuro del sistema dados los importantes cambios demográficos que se daban en la ciudad. Aunque en los documentos disponibles no hay una evidencia explícita de que la decisión de la Junta obedeciera a esas acciones, la injerencia de la comunidad estaba presente indirectamente en el esfuerzo hecho por de León de escribir una propuesta que le resultara atractiva a la comunidad y que generara su apoyo a la iniciativa, algo imprescindible para que la Junta la aprobara ${ }^{44}$. Después, en otro documento relativo a la organización de Hostos, de León hace referencias al Sur del Bronx, a los puertorriqueños, y a las necesidades de educación superior de la comunidad ${ }^{45}$. Aunque en ningún momento menciona actos de movilización o protesta como razones para la creación de la institución o su ubicación en el Sur del Bronx, la injerencia comunitaria está ahí, mediada por sus planteamientos.

Aún más, en 1968, el plan maestro de la Junta para CUNY contemplaba de modo directo la particición de la comunidad en la formulación de

${ }^{41}$ Ibid., n50.

${ }^{42}$ Lillian B. Rubin, "Maximum Feasible Participation: The Origins, Implications, and Present Status," The Annals of the Academy of Political and Social Science vol. 385 (September 1969): 14-29.

${ }^{43}$ Board of Higher Education of the City of New York, Proceedings..., pp. 42-43.

${ }^{44}$ Barry Castro, "Hostos: Report from a Ghetto College," Harvard Educational Review 44:2 (May 1974), p. 273.

${ }^{45}$ Lara-Bonilla, “Crafting...," p. 202. 
planes y políticas relativas a los programas diseñados para minorías en ese momento y en el futuro. Esta participación "desde abajo" se consideraba imprescindible para que las necesidades de la comunidad fuesen propiamente atendidas ${ }^{46}$.

En 1967, una serie de manifestaciones alimentaron el clima social y político en medio del cual la Junta de Educación Superior tomó sus decisiones, en la primavera y el otoño de 1968. Otras manifestaciones en 1969 y 1970, guardaron relación directa con la implementación temprana de la política de libre acceso y la apertura de Hostos.

En la acción de 1967 tomaron parte dos estudiantes que presumiblemente eran Boricuas -Pablo Torres y Gilbert Gutiérrez-y la acción tuvo como propósito establecer un cuerpo gubernamental estudiantil dentro del programa SEEK [Search for Education, Elevation, and Knowledge ${ }^{47}$. En Queens College, un grupo de estudiantes se movilizó en enero de 1968 para defender el programa ${ }^{48}$. En marzo de 68, un grupo de 65 estudiantes se dirigió en autobús hasta la ciudad de Albany, la capital del estado de Nueva York, para apoyar el testimonio del rector Bowker frente a un comité de la legislatura estatal a favor de un aumento en los fondos para SEEK ${ }^{49}$. En abril, un grupo de estudiantes ocupó la oficina del presidente del New York City Community College hasta que él se comprometió a contratar más profesores Afro-Americanos, a ofrecer más cursos en historia Afro-Americana, y a proveer más becas para estudiantes necesitados ${ }^{50}$. En mayo, un grupo de estudiantes y un profesor ocuparon las oficinas de registraduría del Brooklyn College durante 16 horas antes de ser arrestados. Los ocupantes no estaban satisfechos con el compromiso del colegio de admitir 200 estudiantes Afro-Americanos y puertorriqueños en el otoño de 1969 y organizaron la protesta para demandar la admisión de 1.000 estudiantes. Esta acción fue apoyada por una organización de estudiantes Afro-Americana y la llamada Puerto Rican Alliance,

${ }^{46}$ Board of Higher Education of the City of New York, Master Plan...1968..., pp. xv, 56.

${ }^{47}$ Cruz, Liberalism and Identity Politics, p. 78. SEEK se establece en el 1965 con el propósito de ofrecer apoyos académicos y económicos a estudiantes que eran admitidos a la universidad con debilidades que bajo circunstancias normales impedían su admisión o su éxito académico.

${ }^{48}$ Esta acción fue descrita al año siguiente por Will Lissner en "City U. Examines College Dispute," New York Times, January 11, 1969.

${ }^{49}$ M.A. Farber, "Chancellor of City U. Asks State for More Aid," New York Times, March 6, 1968, p. 54L.

${ }^{50}$ J. Anthony Lukas, "Community College Protest is Settled," New York Times, April 27, 1968, p. 20. 
quienes querían innovaciones curriculares que incluyeran el estudio de la experiencia puertorriqueña ${ }^{51}$.

Aunque la razón oficial de la Junta de Educación Superior para justificar la implementación adelantada de la política de libre acceso y de la apertura de Hostos sólo se refiere al éxito de los programas SEEK y College Discovery ${ }^{52}$, las protestas fueron parte del conjunto de movilizaciones que aceleraron el comienzo de la política de libre acceso y que aseguraron que la decisión de establecer el colegio Hostos no fuese en vano. Así, en febrero de 1969, estudiantes del campus de Stony Brook de la universidad estatal [State University of New York], exigieron que el 25\% de la clase de 1970 fuese Afro-Americana y puertorriqueña. Durante ese mes, estudiantes Afro-Americanos demandaron mayor representación de profesores Afro-Americanos en la facultad de Hunter College, y también de consejeros que entendieran la problemática de los Afro-Americanos. Pedían igualmente una biblioteca con materiales relevantes a la experiencia de los Afro-Americanos en Estados Unidos $^{53}$. En abril, el grupo puertorriqueño PRISA [Puerto Rican Students for Action] organizó una protesta conjuntamente con una organización de estudiantes Afro-Americanos en el City College de CUNY. Una de las demandas de esta manifestación fue que se estableciera una escuela dedicada al estudio de la realidad puertorriqueña y Afro-Americana en la ciudad ${ }^{54}$. Esta demanda estaba en consonancia con la decisión de establecer el college de Hostos. Durante la primavera de 1969, grupos de estudiantes Afro-Americanos y puertorriqueños, quizás sin saber que su demanda estaba destinada a ser cumplida en 1975, ejecutaron acciones de protesta dirigidas a presionar a las autoridades para que adoptaran un sistema de admisiones que reservara la mitad de los asientos disponibles en 1970 para estudiantes graduados de las llamadas "escuelas del ghetto" 55 .

En una acción que se relacionaba directamente con el reclamo de un campus propio, un grupo de estudiantes puertorriqueños presentaron una queja en febrero de 1970 en la División Estatal de Derechos Humanos ale-

${ }^{51}$ Peter Kihss, "Brooklyn College Resumes Class after Arrest of 42," New York Times, May 22, 1968, p. 33.

${ }^{52}$ Board of Higher Education of the City of New York, Master Plan...1968..., p. 20. El programa College Discovery es establecido en el 1964 pero para ofrecer apoyo sólo a los estudiantes de los community colleges.

53 “Negro Students Press Demands," New York Times, February 8, 1969, p. 19.

${ }^{54}$ Cruz, Liberalism and Identity Politics, p. 78.

${ }^{55}$ Fred M. Hechinger, “CUNY Begins Vital Test of Open Admissions," New York Times, September 20, 1970, p. 193. 
gando que el programa bilingüe del Bronx Community College en el cual ellos estaban matriculados, era de calidad muy pobre y que ese era uno de los muchos aspectos de la discriminación que sufrían en CUNY ${ }^{56}$. Luego, el 1 de mayo de 1970, cerca de 40 estudiantes puertorriqueños se abarricaron en la oficina del presidente del Brooklyn College de CUNY demandando más plazas para estudiantes puertorriqueños que en ese momento era de 350 de un total de 11.000 estudiantes ${ }^{57}$.

Las protestas de estudiantes que demandaban mayor acceso y representación dentro del sistema universitario de la ciudad no estuvo circunscrito al sector público ni a los puertorriqueños. No es posible determinar aquí qué efecto específico tuvieron acciones estudiantiles de protesta en demanda de mayor acceso de grupos de minoría que ocurrieron en el campus de Brooklyn de Long Island University o en el Wagner College en Staten Island en la aceleración de la decisión de establecer a Hostos, pero su incidencia no puede haber pasado desapercibida por la administración de CUNY. Como mínimo, fueron acciones que ampliaron el ámbito de movilización social bajo el cual Hostos quedó finalmente institucionalizado ${ }^{58}$.

\section{Hostos abre sus puertas}

Hostos abrió sus puertas en condiciones precarias pero no fue el único college cuyas facilidades eran inadecuadas. Gracias al aumento en la matrícula ocasionado por la política de libre acceso, CUNY adquirió 305.000 metros cuadrados de espacio adicional para acomodar a los nuevos estudiantes. Hunter College alquiló cuartos en lo que antes había sido una sinagoga; el Bronx Community College construyó 40 aulas en una antigua pista de hielo; el Kingsborough Community College instaló 36 remolques en su campus; algunas clases se llevaron a cabo en un antiguo supermercado; sesiones de tutoría se efectuaban en un cuarto para almacenar abrigos y algunos estudiantes usaban cabinas de teléfono para estudiar ${ }^{59}$. Hostos abrió sus puertas

56 "Students Protest College Teaching," New York Times, February 25, 1970, p. 36.

${ }^{57}$ Lacey Fosburgh, "40 Puerto Rican Students Lock Brooklyn College Head in Office," New York Times, May 1, 1970, p. 42.

${ }^{58}$ M.A. Farber, "All-Day Revolt at L.I.U. Ends After Negroes Win 6 of 7 Demands," New York Times, April 26, 1968, p. 49; "Wagner College Dean Held 7 Hours by 30 Students Demanding Increased Black Studies," New York Times, April 24, 1970, p. 26.

${ }^{59}$ Farber, "Entrants Put Minority Groups' Rolls...;" Leonard Buder, “Open-Admissions Policy Taxes City U. Resources," New York Times, October 12, 1970, p. 1. 


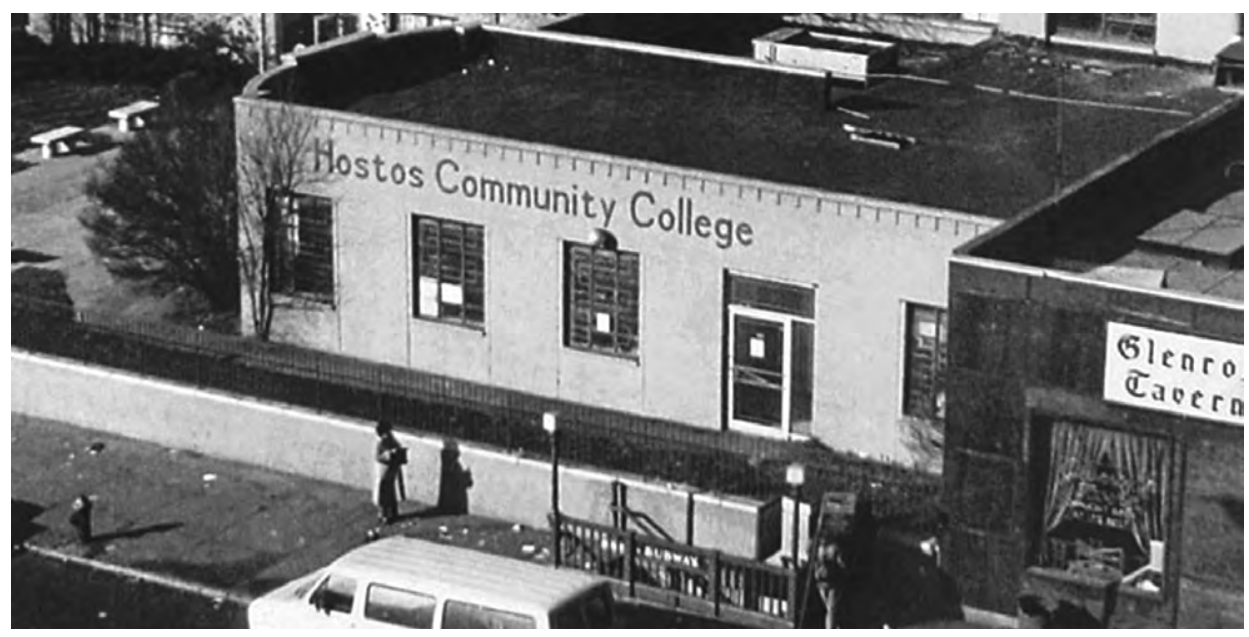

Foto de Hostos: Hostos Community College, 1970. Google Images.

en el edificio de una antigua fábrica de neumáticos localizado en una esquina del Grand Concourse y la parte este de la Calle 149 en el Sur del Bronx ${ }^{60}$.

Hostos tenía la menor cantidad de espacio de entre todas las unidades académicas de CUNY y a los siete años de su establecimiento la situación no había mejorado: 12 metros cuadrados por estudiante comparado con un promedio de 24 metros cuadrados por estudiante en CUNY ${ }^{61}$. El edificio no contaba con facilidades básicas como una cafetería o una librería. En las aulas no había suficientes sillas y tampoco tenían pizarras ${ }^{62}$. Para el año de 1972, cuando Hostos ya contaba con una matrícula de más de 2.000 estudiantes, las condiciones del plantel no habían mejorado y por ello no contribuían en nada a la provisión de una enseñanza de calidad. Para estudiantes y profesores esto daba la impresión de que la institución había sido establecida nada más que para aplacar los movimientos de protesta del 1967-1970, impresión que fue reforzada una vez que la Junta de Educación Superior propuso cerrar a Hostos usando como excusa la existencia de las mismas condiciones que la Junta con su negligencia había creado ${ }^{63}$.

${ }^{60}$ Gerald Meyer, "Save Hostos: Politics and Community Mobilization to Save a College in the Bronx, 1973-1978," CENTRO Journal, XV: I (Spring 2003), p. 74.

${ }^{61}$ Ari L. Goldman, "Head of Hostos Lets No Handicaps Slow Him Down," New York Times, September 21, 1977, p. 23.

${ }^{62}$ C. Gerald Fraser, "College Building on a Base of Hope," New York Times, March 1, 1971, p. 18.

${ }^{63}$ Meyer, “Save Hostos: Politics and Community Mobilization...," p. 74. 
Foto de más espacio:

"Luchemos Unidos / We Struggle United," CUNY Digital History Archive, accessed January 26, 2020, https://cdha. cuny.edu/items/ show/6172.
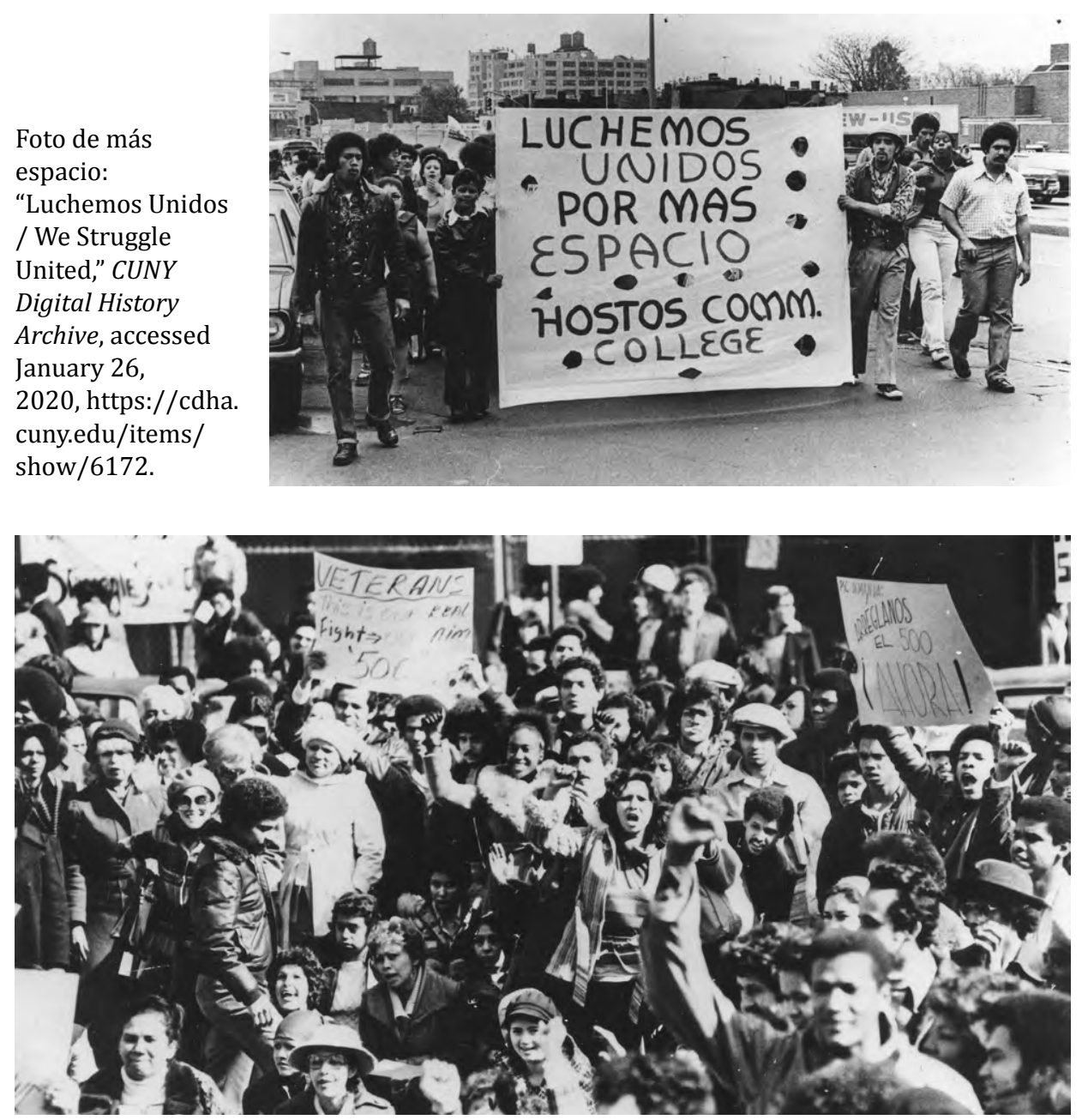

Foto de sit down: "Sit-down in front of Hostos' 500 Building," CUNY Digital History Archive, accessed January 28, 2020, https://cdha.cuny.edu/items/show/6242.

Así fue que en 1973 nació la llamada campaña para obtener un espacio más adecuado para Hostos [Hostos Needs Space] ${ }^{64}$. Por fortuna para los que organizaron esa campaña, justo al frente de la fábrica reformada que albergó a la institución en 1970, había otro edificio de cinco pisos que una compañía de seguros había desalojado cerca del otoño de 1973. De ahí que la campaña

${ }^{64}$ Excepto donde se indique lo contrario, ésta y la sección subsiguiente está basada en el recuento de Meyer, "Save Hostos: Politics and Community Mobilization..." 
se conociera informalmente como aquella que perseguía obtener el número 500 , refiriéndose a la dirección del edificio, localizado en la esquina noreste del Grand Concourse y la Calle 149.

Esta campaña fue llevada a cabo por una coalición de estudiantes y profesores aglutinados en dos organizaciones: la Student Government Organization (SGO) y el Professional Staff Congress (PSC), que era la local en CUNY de la Federación de Maestros de América. Esta alianza ejerció presión sobre la Junta de Educación Superior para que ésta autorizara la mudanza del college al edificio propuesto.

En abril de 1974, la coalición llevó cuatro autobuses llenos de estudiantes a protestar frente a las oficinas de la Junta; en mayo, una marcha por las calles del Sur del Bronx terminó frente a las oficinas del ahora congresista Demócrata puertorriqueño Herman Badillo, quien recibió a un grupo de los manifestantes. En esa reunión los activistas se enteraron de que ellos no eran los únicos que proponían una nueva localización para Hostos.

La reunión con Badillo reveló que la administración de Hostos tenía planes de relocalizarlo permanentemente en un lugar más adecuado. No obstante, la mudanza estaba pendiente de que se resolviera el desacuerdo entre el presidente de Hostos, Cándido de León, y Badillo respecto al lugar a donde la institución debía mudarse. Este impasse "desde arriba" fue resuelto en parte gracias a la movilización de estudiantes y profesores "desde abajo." Al cabo de seis meses de reuniones, asambleas públicas, y viajes a Albany para cabildear a miembros de la legislatura estatal, la compra del edificio número 500 fue aprobada, conjuntamente con una autorización para que Hostos alquilara otras facilidades para proveer espacio de oficina y aulas.

Según Meyer, "el éxito de la coalicion SGO-PSC en adquirir el edificio número 500 dejó claro a la comunidad que la acción política de masas era capaz de obtener logros de envergadura. Esa lección fue la base sobre la cual se erigió la más compleja e importante campaña para salvar a Hostos" ${ }^{\prime 65}$. No obstante, a la altura de 1977, Hostos seguía operando en la antigua fábrica de neumáticos bajo condiciones indeseables ${ }^{66}$. El número 500 seguía inaccesible por falta de fondos para habilitarlo. Entonces, en marzo de 1978, más de 500 estudiantes bloquearon el tráfico en la Calle 149 demandando la reforma del número 500. En ese momento, una nueva coalición denominada Hostos Unido llevaba ya tres meses reuniendo firmas y organizando marchas y manifestaciones. Mientras los estudiantes protestaban, el presidente inte-

${ }^{65}$ Meyer, “Save Hostos: Politics and Community Mobilization...," pp. 78-79.

${ }^{66}$ Goldman, "Head of Hostos..." 
rino de Hostos, Anthony Santiago, y el congresista Herman Badillo, se movían tras bastidores en busca del dinero que se necesitaba ${ }^{67}$. Finalmente, en mayo de 1978 una manifestación estudiantil logró obtener un compromiso por parte del alcalde Demócrata de Nueva York, Ed Koch, de apoyar la reforma de la planta física del número 500 a un costo de $\$ 3.3$ millones $^{68}$.

\section{Salvemos a Hostos}

La campaña para salvar a Hostos [Save Hostos] se desarrolló durante el período de 1975-76, e incluyó el envío masivo de cartas a la Junta de Control Fiscal -el organismo que había sido establecido por la legislatura estatal para manejar la crisis fiscal de la ciudad de Nueva York- a representantes en la legislatura, y a los medios; la colección de firmas en la comunidad en apoyo a Hostos -un esfuerzo que generó más de 5.000 muestras de apoyo individual ${ }^{69}$-; manifestaciones de estudiantes y profesores frente al ayuntamiento de la ciudad; actividades para recaudar fondos para la campaña; testimonios en vistas públicas frente a la Junta de Educación Superior; y la publicación de un panfleto con datos sobre la institución que fue diseminado ampliamente para argumentar el caso a favor de Hostos.

Esta campaña, que comenzó en diciembre de 1975 con una manifestación comunal en la que participaron más de mil personas ${ }^{70}$, combinó exitosamente esfuerzos "desde abajo" y "desde arriba". La movilización de masas fue bien vista en gran parte porque su objetivo era considerado legítimo y, hasta cierto punto conservador, en vez de radical, que suele ser una razón importante para que una movilización social quede condenada al fracaso. Entre las organizaciones de base que participaron en la campaña estaban dos cuya reputación y legitimidad era incuestionable: la United Bronx Parents y la iglesia local St. Ann. Además participaron el Partido Socialista Puertorriqueño y su frente estudiantil, la Federación Universitaria Socialista; el Puente de Unidad Latina, que era un grupo de ex-convictos; un grupo de veteranos de Vietnam;

${ }^{67}$ Michael Sterne, "Space Need Upsets A College In Bronx," New York Times, January 29, 1978, p. 27; Michael Sterne, "500 Marchers Protest the Delay on Annex at Hostos," New York Times, March 10, 1978, p. B3; Conrado Hernández, "Piden se Incorpore a Escuela 'Hostos' Edificio Compro CUNY," El Diario-La Prensa, 10 de marzo de 1978, p. 2.

${ }^{68}$ Sam Weiss, "Koch Is To Approve Hostos Renovation," New York Times, July 15, 1978, p. 21.

${ }^{69}$ Ramón J. Jiménez, "Hostos Community College: Battle of the Seventies," CENTRO Journal, XV:I (Spring 2003), p. 101.

${ }^{70}$ Ibid., pp. 101-102. 


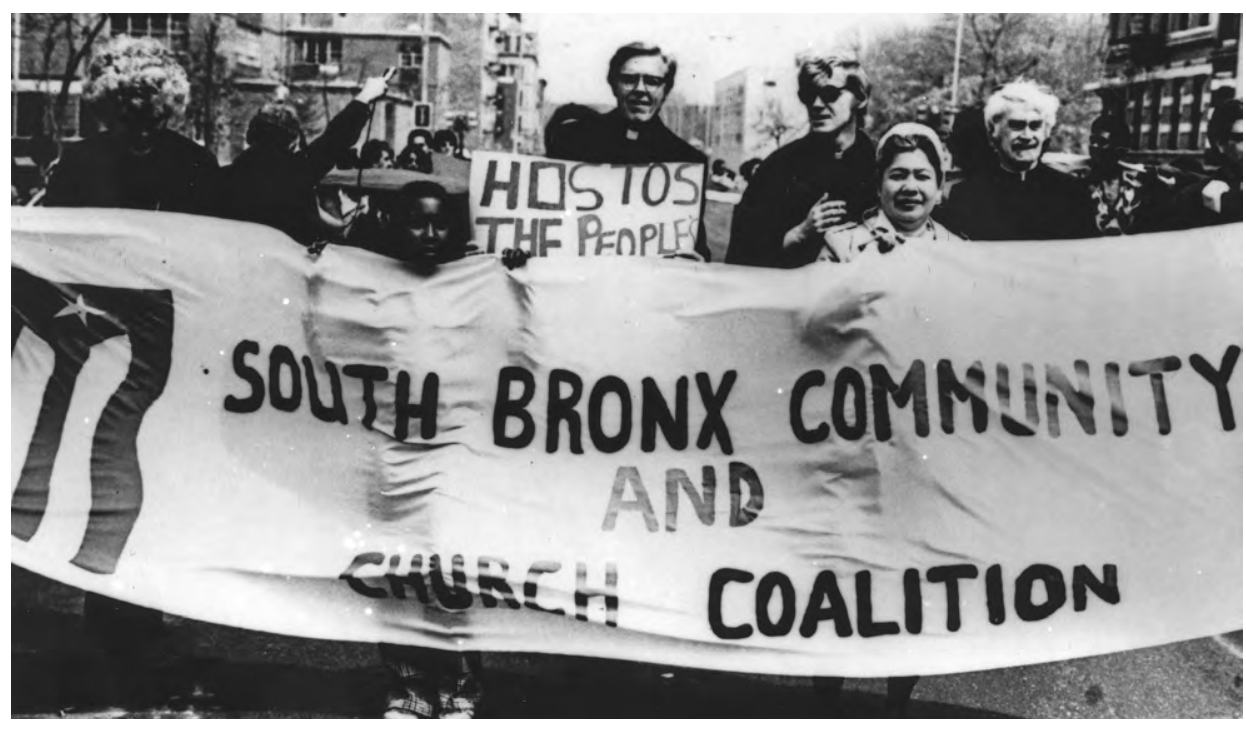

Foto de coalición iglesia/comunidad: "South Bronx Community and Church Coalition," CUNY Digital History Archive, accessed January 26, 2020, https://cdha.cuny.edu/items/show/6152.

el llamado People's Park, que era una pandilla local; ${ }^{71}$ la South Bronx Community Corporation y la organización educativa ASPIRA. ${ }^{72}$

A pesar de que la Coalición Comunitaria Para Salvar a Hostos, que se unió al Save Hostos Committee (SHC) y que fue responsable de algunas de las manifestaciones más militantes y controvertidas de la campaña, estuvo influenciada por el Partido Socialista Puertorriqueño, esto no fue determinante para la campaña. De hecho, uno de sus actos -la ocupación de las aulas el 25 de marzo de 1976- estuvo a punto de descarrilar la campaña al provocar una división entre grupos de estudiantes y facultad ${ }^{73}$, pero en vez de hacerlo lo que logró fue provocar una mayor cobertura de la lucha para salvar a Hostos en los medios noticiosos.

"Desde arriba," el apoyo fue provisto por figuras públicas importantes como los congresistas del Bronx Herman Badillo y Jonathan Bingham, el congresista Afro-Americano Charles Rangel y sus colegas Mario Biaggi y Bella Abzug, el líder del consejo municipal Paul O’Dwyer, los presidentes de los municipios de Manhattan y de Queens, Percy Sutton y Donald Manes, respectiva-

\footnotetext{
${ }^{71}$ Ibid., pp. 101-103.

72 “Protesters Occupy Hostos 10th Day to Bar Closing," New York Times, April 4, 1976, p. 40.

73 "Faculty at Hostos Bids President End Building's Takeover, New York Times, April 11, 1976, p. 44.
} 
mente, todos miembros del Partido Demócrata; el presidente del PSC, Irwin Polishook; el asambleísta estatal Seymore Posner y el concejal Ramón S. Vélez, ambos Demócratas, así como también por figuras del mundo empresarial y comercial. En un momento dado, hasta el mismo gobernador de Nueva York, cuya posición respecto al apoyo del estado a CUNY era ambivalente ${ }^{74}$, declaró que un programa como el de Hostos valía la pena ser preservado ${ }^{75}$.

Quedaba claro que cerrar el colegio implicaría una pérdida de entre $\$ 2$ a $\$ 3$ millones al año en ganancias y la pérdida de una posible nómina de $\$ 20$ millones anualmente, y por eso los líderes del Citibank, del equipo de beisbol Los Yanquees, de las tiendas Hearn y Alexander's, de la Asociación de Comerciantes de la Calle 149 y de la Cámara de Comercio del Bronx, declararon públicamente su apoyo a Hostos, mientras que otros ya estaban en las actas públicas favoreciendo su expansión ${ }^{76}$. En contraste, el alcalde Demócrata de la ciudad, Abraham Beame, proponía, no solamente hacer recortes aquí y allá, sino eliminar por completo el subsidio de la ciudad a los llamados "senior colleges" del sistema para así ahorrar $\$ 140$ millones $^{77}$.

El 8 de marzo de 1976, una congregación que la policía estimó en unos 3.500 participantes, se aglutinó frente al edificio del Graduate Center de CUNY en la Calle 42, donde la Junta de Educación Superior celebraba una vista pública para considerar la propuesta del nuevo rector de CUNY, Robert J. Kibbee, para reestructurar la universidad. Los participantes incluían a padres, estudiantes, y profesores de las seis unidades que Kibbee proponía eliminar. Entre ellos, Gloria Granados, una madre de tres niños que estudiaba en Hostos le dijo a la prensa: "Yo estoy aquí para que no cierren [a Hostos]," mientras que la multitud gritaba: “Ellos dicen recortes, nosotros decimos a luchar!;” “Ellos dicen vocacional, nosotros decimos profesional!" Ésta no fue una protesta cualquiera pues entre los oradores estaban tres de los congresistas que apoyaban a Hostos: Herman Badillo, Mario Biaggi, y Bella Abzug ${ }^{78}$.

${ }^{74}$ Linda Greenhouse, “Carey Rules Out Rise in City U. Aid,” New York Times, May 21, 1976, p. 1.

${ }^{75}$ Maurice Carroll, “Carey Seeks to Pressure Board on City U. Tuition," New York Times, May 31, 1976, p. 1.

${ }^{76}$ Meyer, "Save Hostos: Politics and Community Mobilization...," p. 80; Michael Sterne, "A Plan Would Give South Bronx Stores, a Campus and 3,000 jobs," New York Times, March 4, 1977, p. 21.

77 "Beame Asserting His Right to Be the Hatchet Man," New York Times, March 28, 1976, p. 150.

${ }^{78}$ David Vidal, "3,500 Chant Outside 42d St. Hearing," New York Times, March 9, 1976, p. 36; “Planned City U. Cuts Spur Protest," New York Times, March 9, 1976, p. 69. 


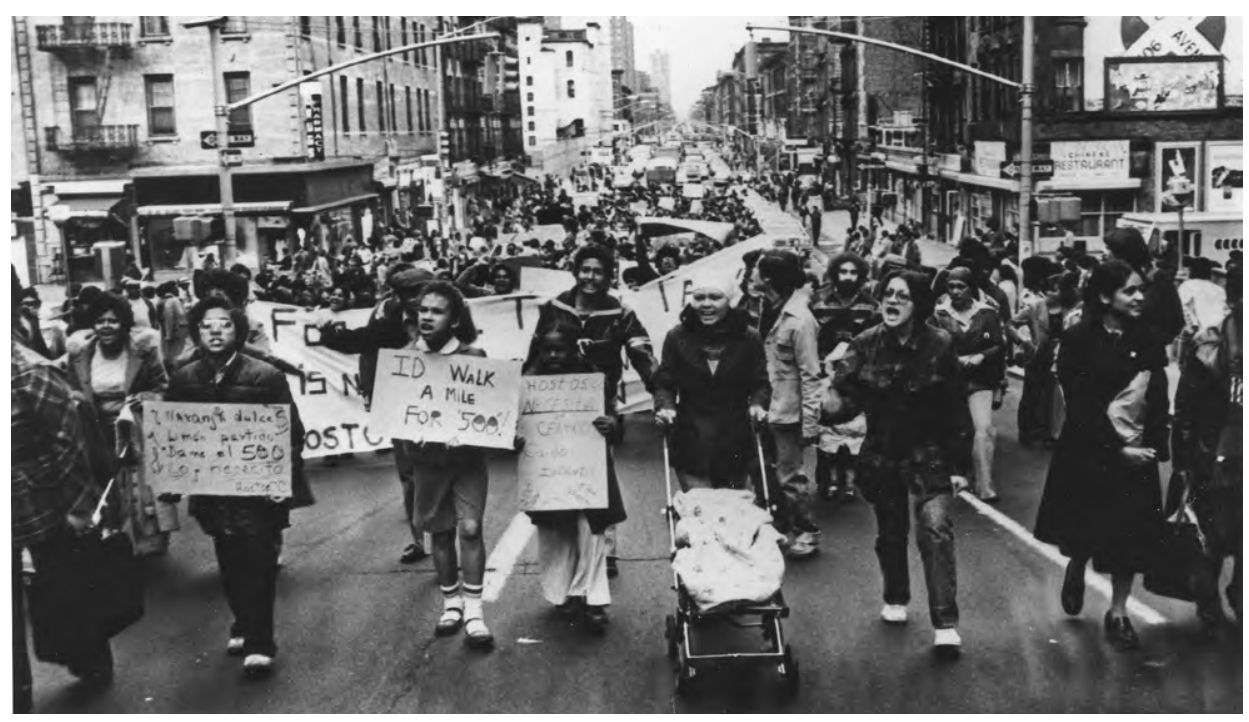

Foto de marcha: "March to Gracie Mansion," CUNY Digital History Archive, accessed January 26, 2020, https://cdha.cuny.edu/items/show/6222.

La Junta hizo caso omiso del reclamo popular y apoyó la propuesta de Kibbee. Para una mayoría de la Junta una cantidad de \$60 millones era razón suficiente para clausurar una institución educativa que en un corto plazo de tiempo se había convertido, según lo indicaban los propios estudiantes, ${ }^{79} \mathrm{en}$ un faro de esperanza social para miles de jóvenes puertorriqueños y AfroAmericanos en el Bronx ${ }^{80}$ Por supuesto, $\$ 60$ millones es una cantidad sustancial pero el ahorro por el cierre de Hostos se estimaba en sólo \$3.7 millones lo cual sugería que la razón verdadera para su cierre no era económica ${ }^{81}$. De otra parte, y pensando precisamente en el impacto que el cierre de Hostos iba a tener en la comunidad, los miembros de la Junta que se oponían al plan de Kibbee ofrecieron una alternativa. Según ellos, su propuesta iba a suponer un ahorro de $\$ 90$ millones sin tener que eliminar ninguna de las unidades que Kibbee quería cerrar ${ }^{82}$.

${ }^{79}$ David Vidal, “...While Hostos Colege Resists Its Elimination,” New York Times, March 6, 1976, p. 36.

${ }^{80}$ Edward B. Fiske, "City U. Board Backs Plan by Kibbee," New York Times, March 24, 1976, p. 82; Barry Castro, “Hostos: Report from a Ghetto College...," p. 290.

${ }^{81}$ Judith Cummings, "Some of City U.'s Colleges Uncertain of Their Status," New York Times, March 15, 1976, p. 34.

${ }^{82}$ Judith Cummings, "Alternative Offered to Kibbee's City U. Proposal," New York Times, April 1, 1976, p. 34. 
El 4 de abril de 1976, la Junta de Educación Superior, menoscabando la oposición de sus miembros puertorriqueños y Afro-Americanos, adoptó una resolución autorizando la consolidación de Hostos y el Bronx Community College, efectivamente asegurando la disolución de Hostos. Dicha resolución fue condenada por la facultad y los funcionarios de Hostos como racista. El 27 de abril, una organización llamada Comité de Defensa de los Derechos Democráticos de los Puertorriqueños lidereó una marcha desde la Calle 116 y la Avenida Lexington en El Barrio, hasta las oficinas de la Junta de Control Fiscal en la Calle 56 y la Avenida de las Américas. Esta demostración fue muy parecida a la de la foto de la marcha a Gracie Mansion reproducida aquí, que se celebró durante la campaña para obtener el edificio número $500^{83}$.

Más tarde, el 10 de mayo, un contingente de aproximadamente 3.000 personas marcharon a lo largo de más de sesenta cuadras gritando " $\mathrm{i}$ Salvemos a Hostos!" La hoja suelta usada por el Comité para promover la marcha leía: "Acusamos a los miembros de la Junta de Control Fiscal de crímenes contra la comunidad," y señalaba al

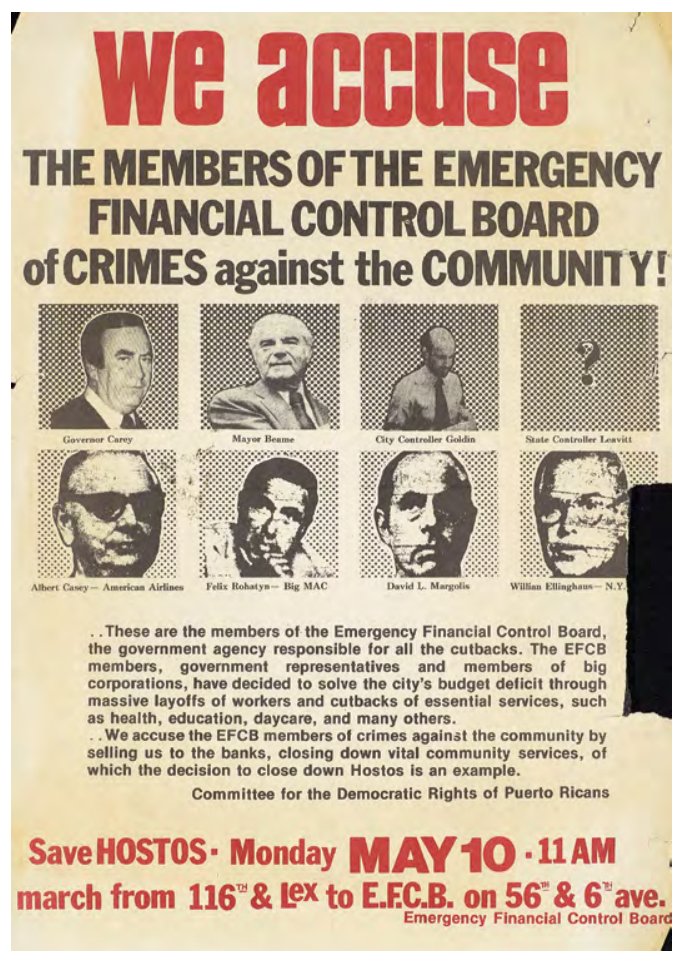

Hoja suelta we accuse: Community Coalition to Save Hostos, " "We Accuse"," CUNY Digital History Archive, accessed January 28, 2020, https://cdha. cuny.edu/items/show/7492. gobernador Demócrata Hugh Carey y al alcalde Abraham Beame como los responsables por los recortes presupuestarios que habían contribuido a que la Junta de Educación Superior decidiera eliminar a Hostos.

Mientras tanto, miembros de la administración y de la facultad de Hostos viajaron a Albany para cabildear a favor de su permanencia. Allí fueron

${ }^{83}$ El costo de la adquisición de una foto de la marcha del 27 de abril del archivo del New York Times resultó ser prohibitivo. 
muy bien recibidos por los legisladores puertorriqueños y Afro-Americanos. Las organizaciones legislativas de ambos declararon su simpatía por la causa de Hostos y la oficina del senador estatal Demócrata Robert García se convirtió en la sede informal del SHC. El asambleísta Demócrata José Serrano apoyó la recuperación del presupuesto de Hostos en el presupuesto del estado y el asambleísta Demócrata Louis Nine introdujo el punto legislativo que articulaba la restauración.

A fin de cuentas, fue en la legislatura estatal donde se decidió la suerte de Hostos, es decir, donde culminó el esfuerzo combinado de "los de abajo" y "los de arriba" en la lucha para salvar el college. La legislatura era el organismo que tenía el poder de abrir o cerrar las unidades de CUNY y los legisladores puertorriqueños y Afro-Americanos le dejaron saber al Gobernador Carey que no iban a votar a favor de su presupuesto a menos que él garantizara la continuidad de Hostos y la del Medgar Evers Community College que servía a un estudiantado mayoritariamente Afro-Americano. Así, el plan de ayuda provisto por el estado, valorado en $\$ 3$ millones para su presupuesto operacional y en $\$ 8$ millones para abaratar el costo de la recién impuesta matrícula ${ }^{84}$, fue lo que evitó que Hostos cerrara sus puertas ${ }^{85}$.

\section{Un éxito conjunto}

La lucha para poner en marcha Hostos fue similar a la lucha para salvarlo. Es posible que el college se hubiera establecido sin las presiones que estudiantes, activistas, y residentes ejercieron "desde abajo," gracias a la visión de líderes como Albert Bowker y a la injerencia de figuras como Herman Badillo, Louis Núñez, y Cándido de León. La realidad, sin embargo, es que esas presiones, que fueron articuladas en el proceso de toma de decisiones de manera indirecta, directa y mediada, fueron un elemento constitutivo importante y novedoso que fue a su vez parte de un contexto más amplio de lucha y movilización social contra la guerra, por la preservación del medioambiente, y por los derechos democráticos de las mujeres y los homosexuales.

Que el rescate del college hubiese sido posible sin la movilización de la comunidad es una interrogante que no tiene contestación definitiva. Aún

\footnotetext{
${ }^{84}$ Edward B. Fiske, "Tuition Imposed at City U., Endind A 129-Year Policy," New York Times, June 2, 1976, p. 1.

${ }^{85}$ Robert E. Tomasson, "Hostos, rescued at the Last Moment, Is Looking Forward to Another Year," New York Times, June 15, 1976, p. 41.
} 
así, el sentido común y la experiencia sugieren que, dada la crisis fiscal de la ciudad y el poder de la Junta de Control Fiscal de efectuar los cortes presupuestarios que con razón o sin ella estimara necesarios, si su injerencia -así como la de la Junta de Educación Superior- no hubiese estado sujeta al escrutinio público y a la acción ciudadana, es muy posible que Hostos hubiese sido clausurado.

Ya en 1972, Hostos había perdido un gran aliado una vez que Robert J. Kibbee reemplazó al rector Bowker. Mucho antes de que la crisis fiscal de la ciudad le llevara a plantear eliminar a Hostos, Kibbee se había mostrado dispuesto a sacrificar a la institución en el altar de la crisis presupuestaria de CUNY y en 1974 autorizó recortes al sistema de $\$ 114.000$ que provocaron una protesta masiva de la comunidad ${ }^{86}$.

Kibbee no logró eliminar Hostos pero si no lo hizo, no fue porque cambió de parecer a base de argumentos razonables. Cuando él declaró que la crisis fiscal requería que la universidad redefiniera "lo que hacía y para quién lo hacía," lo que propuso fue reducir la facultad y el estudiantado en un $20 \%$ mediante la eliminación de lo que él consideraba "programas innecesarios o redundantes" ${ }^{\prime 87}$. Si bien es cierto que en un momento dado él estuvo dispuesto a presionar para lograr un aumento en la asignación presupuestaria de la ciudad a CUNY, también es cierto que esto era sólo una postura que escondía su disposición a aceptar una asignación de $\$ 40$ millones, que era una reducción de $\$ 72$ millones por debajo de lo que la universidad necesitaba ${ }^{88}$.

En última instancia, el caso de Hostos sugiere que en el proceso de establecer y mantener una institución de educación superior que responda directamente a las necesidades de un grupo subalterno, la iniciativa de "los de arriba," que es la que más frecuentemente se asocia con este tipo de desarrollo institucional, no es necesariamente suficiente ni fiable. Durante el proceso para asegurar que la Junta iba a cumplir su palabra de establecer la institución y también salvarla del cierre, muchos estaban convencidos que no se podía confíar totalmente en las elites administrativas y por ello planteaban que de la única manera que iban a lograr apoyo institucional era a través de la militancia "desde abajo" ${ }^{89}$. Además, la prueba estaba en

${ }^{86}$ Peter Kihss, "9\% of 38,555 City U. Freshmen Are Getting Aid From Welfare," New York Times, January 18, 1972, p. 28; Gene L. Maeroff, "City U. Adopts Budget-Cut Measures," New York Times, December 13, 1974, p. 51.

${ }^{87}$ Edward B. Fiske, "City University Rethinks Goals," New York Times, October 19, 1975, p. 1.

${ }^{88}$ Fred Ferretti, "Politics, Budgets and Public relations at City U.," New York Times, December 29, 1976, p. 29.

89 "More Aid Asked for Puerto Rican Students Here," New York Times, February 3, 1971, p. 41. 
los hechos: desde el día en que los estudiantes de Hostos organizaron su primeras protestas en marzo y abril de 1971, quedó claro que la militancia producía resultados ${ }^{90}$.

Las decisiones que establecieron y salvaron a Hostos fueron tomadas "desde arriba". Pero fue "desde abajo" y en un contexto favorable que el caso de Hostos se argumentó y defendió, de forma indirecta y mediada dentro de la Junta y de forma explícita ante la opinión pública, llegando así a la atención del conjunto de elites que tenían la influencia y el poder de decisión para dictaminar el curso de la institución. En el caso de la lucha para salvar a Hostos, ¿cómo habrían actuado esas elites si la comunidad no se hubiese movilizado? Como todo buen contrahecho, no hay contestación. No obstante, lo que la documentación disponible deja claro es que, en el caso de Hostos, la movilización de base produjo la información, los datos, y la pasión que hacía falta para que las elites al menos ejercieran una opción entre salvarlo o eliminarlo. Algo adicional que se puede deducir de este recuento es que, como ha indicado Heller, para que la movilización social sea efectiva es mejor decir la verdad a través del poder que confrontar al poder con la verdad sólo desde la calle ${ }^{91}$.

Sin duda, las instituciones del estado y la sociedad son esferas discursivas y de acción que están interconectadas y así las acciones que surgen "desde abajo" son siempre una fuente potencial de cambio a nivel tanto de las instituciones como de la sociedad ${ }^{92}$. Pero exactamente cómo y cúando esto sucede o es más o menos probable que sucederá, no siempre se sabe. El caso de Hostos le da sustancia a la idea de que en períodos de movilización social masiva las instituciones del estado se ven obligadas a tomar nota y a responder. Este caso sugiere, además, que para que "los de arriba" respondan a tono con las demandas de "los de abajo", es preferible que haya una conexión palpable entre unos y otros, en vez de una situación en la cual "los de abajo" se limitan a proferir demandas desde espacios extra-institucio-

${ }^{90}$ Antes del establecimiento de Hostos, otro ejemplo de esto fue el nombramiento del educador Afro-Americano Dr. Ralph Hewitt Lee, como director del programa SEEK en Queens College efectuado en septiembre de 1969, como resultado directo de protestas estudiantiles en el 1968. Ver "Negro Chosen Head of SEEK Program at Queens College," New York Times, September 4, 1969, p. 40. A principios del 1971, como resultado de sus protestas, los estudiantes de Hostos lograron que les dejaran enarbolar banderas revolucionarias en el edificio y forzaron la renuncia del entonces presidente Nazry Michelen. Ver Fraser, "College Building...;" M.A. Farber, "Head of a College in Bronx Resigns," New York Times, April 27, 1971, p. 39.

${ }^{91}$ Nathan Heller, "Out of Action," The New Yorker, August 21, 2017, p. 76.

${ }^{92}$ Ver I.M. Young, Inclusion and Democracy (Oxford: Oxford University Press, 2002), p. 166 y M.A. Haddad, "The state-in-society approach to the study of democratization with examples from Japan," Democratization 17(5) (2010). 
nales a "los de arriba," sin un vínculo que aumente la probabilidad de que sus acciones se traduzcan en resultados de política pública o, como en este caso, institucionales.

\section{Bibliografía}

Archivos

Archives of the Puerto Rican Diaspora, Hunter College, City University of New York

CUNY Digital History Archive

The Municipal Library, City of New York

New York State Library and Archives

Periódicos y Revistas

El Diario-La Prensa

The New Yorker Magazine

The New York Times

Libros, artículos y otros documentos

ACosTA-BELÉn, EDNA, et al. "Adiós Borinquen querida:" La diáspora puertorriqueña, su historia y sus aportaciones. Albany, NY: CELAC, 2000.

BOARD OF Higher EduCATION OF THE CiTy OF NEW YoRK. Master Plan of the Board of Higher Education for the City University of New York, 1968: 1970. September 1, 1970, New York State Library and Archives.

BoARd OF Higher Education OF THE City OF NEW YoRK. Master Plan of the Board of Higher Education for the City University of New York, 1968. July 1, 1968, New York State Library and Archives.

BoARd of Higher Education of THE City OF NeW YoRk. Proceedings of the Board of Higher Education of the City of New York, 1968. The Municipal Library, City of New York.

BRIER, STEPHEN. "Why the History of CUNY Matters: Using the CUNY Digital History Archive to Teach CUNY's Past". Radical Teacher 108 (Spring 2017): 28-35.

CASTRO, BARRY. "Hostos: Report from a Ghetto College", Harvard Educational Review 44:2 (May 1974): 270-294. 
CRUZ, JosÉ E. Liberalism and Identity Politics, Puerto Rican Community Mobilization and Collective Action in New York City. New York: Centro Press, 2019.

Francis-Fallon, Benjamin. The Rise of the Latino Vote, A History. Cambridge, MA: Harvard University Press, 2019.

Giraudoux, JEAn. Tiger at the Gates, translated by Christopher Fry. New York: Oxford University Press, 1955.

HADDAD, M.A. "The state-in-society approach to the study of democratization with examples from Japan”. Democratization 17(5) (2010): 997-1023. Heller, Nathan. "Out of Action". The New Yorker. August 21, 2017: 70-77. JimÉnEZ, RAMÓn J. "Hostos Community College: Battle of the Seventies". CENTRO Journal, XV: I (Spring 2003): 99-111.

LARA-Bonilla, InMACUladA. "Crafting a Latina/o Higher Education Rights Discourse in New York: The Founding and "Saving" of Eugenio María de Hostos Community College", New York History 97: 2 (Spring 2016): 187-228.

Lopez, Tomas. "An American Necessity:" The Politics of Survival at Hostos Community College, New York, 1970-78. Honors Thesis, Department of History, Duke University, April 14, 2006.

MeYer, Gerald. "Save Hostos: Politics and Community Mobilization to Save a College in the Bronx, 1973-1978". CENTRO Journal, XV:I (Spring 2003): 73-97.

Padilla, Felix. Puerto Rican Chicago. Notre Dame, IN: University of Notre Dame Press, 1987.

Rodríguez-Fraticelli, Carlos. "Hostos Community College and the Puerto Rican Struggle for Equity in Education", CENTRO Journal of the Center for Puerto Rican Studies II:2 (1988): 23-32.

Rodríguez-MuÑIz, Michael. "Riots and Remembrance: Puerto Rican Chicago and the Politics of Interruption". CENTRO Journal XXVIII: II (Fall 2016): 204-217.

Rubin, Lillian B. "Maximum Feasible Participation: The Origins, Implications, and Present Status." The Annals of the Academy of Political and Social Science vol. 385 (September 1969): 14-29.

Serrano, Basilio. "'Rifle, Cañón, y Escopeta', A Chronicle of the Puerto Rican Student Union." En The Puerto Rican Movement, Voices from the Diaspora, editado por Andrés Torres y José E. Velázquez, pp. 124-143. Philadelphia: Temple University Press, 1998.

Skowronek, Stephen And Karen Orren. The Search for American Political Development. Cambridge, UK: Cambridge University Press, 2004.

Young, I.M. Inclusion and Democracy. Oxford: Oxford University Press, 2002. 